\begin{abstract}
Iranica
Abstracta Iranica Revue bibliographique pour le domaine irano-aryen

Volume 34-35-36 | 2017

Comptes rendus des publications de 2011-2013
\end{abstract}

\title{
Shahzad Bashir. Sufi Bodies. Religion and Society in Medieval Islam
}

\section{Pierre Lory}

\section{(2) OpenEdition}

Édition électronique

URL : http://journals.openedition.org/abstractairanica/41934

DOI : 10.4000/abstractairanica.41934

ISSN : 1961-960X

Éditeur :

CNRS (UMR 7528 Mondes iraniens et indiens), Éditions de l'IFRI

Référence électronique

Pierre Lory, "Shahzad Bashir. Sufi Bodies. Religion and Society in Medieval Islam », Abstracta Iranica [En ligne], Volume 34-35-36 | 2017, document 1, mis en ligne le 30 décembre 2016, consulté le 30 septembre 2020. URL : http://journals.openedition.org/abstractairanica/41934 ; DOI : https://doi.org/ 10.4000/abstractairanica.41934

Ce document a été généré automatiquement le 30 septembre 2020.

Tous droits réservés 


\title{
Shahzad Bashir. Sufi Bodies. Religion and Society in Medieval Islam
}

\author{
Pierre Lory
}

\section{RÉFÉRENCE}

Shahzad Bashir. Sufi Bodies. Religion and Society in Medieval Islam. New York, Columbia University Press, 2011, 274 p.

1 L'A. entreprend ici une analyse originale de la vie spirituelle soufie. Laissant de côté les développements doctrinaux ou les expressions lyriques de la poésie mystique, il s'attache à souligner la pertinence des récits qui se rapportent au corps - des maîtres et des disciples. Ces récits, en dépit du merveilleux qu'ils contiennent souvent, et même à cause de lui, nous transmettent des messages pleins de sens sur le vécu de ces hommes. $\mathrm{ShB}$ se focalise sur les textes hagiographiques de langue persane des $\mathrm{XIV}^{\mathrm{e}}$ et $\mathrm{XV}^{\mathrm{e}}$ siècles. Ainsi est mise en relief la notion de corps elle-même - matériel, mais aussi animé par un voire plusieurs corps subtils, et par l'esprit, le rūh ; corps imaginal donc autant que corpusculaire, faisant interface avec le monde invisible. La discipline soufie consiste précisément à "spiritualiser » le corps, à le préparer à son destin eschatologique. Des développements riches sont consacrés à la notion d'amour ; à l'alimentation et aux prodiges entourant celle des saints (chap. 6). Mais c'est le corps des maîtres qui a bien sûr le plus retenu l'hagiographie, avec les capacités prodigieuses qu'ils manifestent (déplacements miraculeux, bilocation etc), ainsi que le pouvoir pratiquement illimité que ces maîtres possèdent sur les facultés physiques et mentales des autres hommes, de leurs disciples en particulier. Les exemples nombreux et des reproductions de miniatures persanes étayent les démonstrations de l'auteur. 


\section{AUTEURS}

PIERRE LORY

EPHE, Paris 